\title{
Estimate of Leaf Chlorophyll and Nitrogen Content in Asian Pear (Pyrus serotina Rehd.) by CCM-200
}

\author{
Mostafa GHASEMI, Kazem ARZANI, Abbas YADOLLAHI, Shiva \\ GHASEMI, Saadat SARIKHANI KHORRAMI
}

Tarbiat Modares University, Department of Horticultural Science, Faculty of Agriculture, Tehran, Iran; ghasemi.mostafa12@yahoo.com

\begin{abstract}
In many cases evaluation of chlorophyll and nitrogen content in plants need to destructive methods, more time and organic solvents. Application of chlorophyll meters save time and resources. The aim of this study was estimating of chlorophyll and nitrogen content in Asian pear leaves using non-destructive method and rapid quantification of chlorophyll by chlorophyll content meter (CCM200). This study was conducted on 8 years old Asian pear trees during June 2008 in Tehran, Iran. To develop our regression model, the chlorophyll meter data were correlated with extracted chlorophyll and nitrogen content data obtained from DMSO and Kejeldal methods, respectively. The results showed that, there was positive and linear correlation between CCM-200 data and chlorophyll $a$ $\left(\mathrm{R}^{2}=0.7183\right)$, chlorophyll $b\left(\mathrm{R}^{2}=0.8523\right)$, total chlorophyll $\left(\mathrm{R}^{2}=0.90\right)$, and total nitrogen content $\left(\mathrm{R}^{2}=0.76\right)$ in Asian pear leaves. Thus, it can be concluded that, CCM-200 can be used in order to predict both chlorophyll and nitrogen content in Asian pear leaves.
\end{abstract}

Keywords: Asian pear, chlorophyll, chlorophyll meter, nitrogen

\section{Introduction}

Nitrogen is one of the most important macro nutrients and plays critical role in vegetative growth, flowering and fruit development (Shaahan et al., 1999). Changes in chlorophyll content occur as a result of nutrient deficiency, especially nitrogen with consider to this point that nitrogen is leached from soil quickly. Nitrogen deficiency decreases chlorophyll content due to chlorophyll decomposition in plant leaves (Kowalczyk-Jusko and Koscik, 2002; Shaahan et al., 1999). Low concentrations of chlorophyll limit photosynthetic potential directly (Richardson et al., 2002). Leaf chlorophyll content is a good indicator of photosynthesis activity, mutations, stress condition (Naumann et al., 2008), and nutritional status of plants (Wu et al., 2008). Wright et al. (2009) examined the possibility of using chlorophyll $a$ fluorescence to measure postharvest water loss of grape berries non-destructively. Chlorophyll content estimation by laboratory methods is destructive and need to time and also chemical materials (Chang and Robinson, 2003). Since chlorophyll concentration is correlated with leaf nitrogen concentration, the instruments which are used to evaluate chlorophyll concentration such as SPAD-502 (Minolta, Japan) and Chlorophyll content meter CCM-200, have been designed to determine nitrogen content (Pavan et al., 2004). Such devices provide a quick, simple and non-destructive method to in situ chlorophyll content estimation (Kowalczyk-Jusko and Koscik, 2002; Richardson et al., 2002). Regarding the relationship between chlorophyll content and leaf nitrogen content, chlorophyll meter can be used to improve fertilizer man- agement (Richardson et al., 2002). A close correlations between chlorophyll meter with foliar nitrogen and total extracted chlorophyll has been reported in several fruit trees such as mango, mandarin, guava and grapevine (Shaahan et al., 1999), also in other crops such tobacco leaves (Kowalczyk-Jusko and Koscik, 2002) and sugar maple (Van den Berg and Perkins, 2004). Change and Robinson (2003) also reported significant correlations between CCM-200 data and nitrogen content of four woody species. Therefore a correlation between chlorophyll content readings and $\mathrm{N}$ content in a plant will be helpful for growers to monitor nitrogen status of plants.

CCM-200 calculates the chlorophyll content index (CCI), which is defined as the ratio of percentage of transmission a $935 \mathrm{~nm}$ to $635 \mathrm{~nm}$ through leaf tissues (Richardson et al., 2002). Despite Asian pears need a very precise nutrient schedule during growth season there is no nondistractive method to evaluate nutritional status of this crop. Hence the objective of this study was to isolate the possible correlations between chlorophyll meter readings and total chlorophyll measured via DMSO and nitrogen content of Asian pear leaves to improve nutrient scheduling in order to orchard management.

\section{Materials and methods}

This study was conducted on eighteen Asian pear (Pyrus serotina Rehd) trees in a experimental orchard in Tehran province $\left(35^{\circ} 45^{\prime} \mathrm{N}, 51^{\circ} 8^{\prime} \mathrm{E}\right)$, Iran, during June 2008. Chlorophyll meter (Opti-sciences CCM 200, USA) which calculates chlorophyll content index (CCI) 
92

based on the ratio of transmittance measurement at 660 and $940 \mathrm{~nm}$ was used. Twelve measurements with CCM200 were made on four healthy mature leaves of Asian pear trees from the middle of non fruiting branches and then nitrogen content of these leaves were analyzed via Kejeldal method. At the same time five readings also were taken for chlorophyll analysis. Then all leaves brought to laboratory for further experiments.

\section{Chlorophyll determination}

Dimethyl sulfoxide solvent (DMSO) was used for chlorophyll extraction from five leaf discs in dark according to described method by Hiscox and Israelstam (1979). Absorbance of extracts was read by Beckman grating spectrophotometer (model U-1100, ltitach, Ctd, tokyo, Japan) at 645 and $663 \mathrm{~nm}$. Chlorophyll $a\left(\mathrm{mg} / \mathrm{cm}^{-2}\right)$, Chlorophyll $b\left(\mathrm{mg} / \mathrm{cm}^{-2}\right)$ and total chlorophyll content $\left(\mathrm{mg} / \mathrm{cm}^{-2}\right)$ were calculated from absorbance at $663 \mathrm{~nm}$ and $645 \mathrm{~nm} \mathrm{ac}$ cording to Arnon's (1949) equations:

Chlorophyll $a=(\mathrm{ml}$ solvent $)[(0.0127 \times$ Absorbance 663) - (0.00269 Absorbance 645)]/Leaf area $\left(\mathrm{cm}^{2}\right)$

Chlorophyll $b=(\mathrm{ml}$ solvent $)[(0.0229 \times$ Absorbance 645) - (0.00468 Absorbance 663)]/Leaf area $\left(\mathrm{cm}^{2}\right)$

Total chlorophyll content $=(\mathrm{ml}$ solvent $)(0.0202$ $\times$ Absorbance 645$)+(0.00802$ Absorbance 663) $] /$ Leaf $\operatorname{area}\left(\mathrm{cm}^{2}\right)$

I

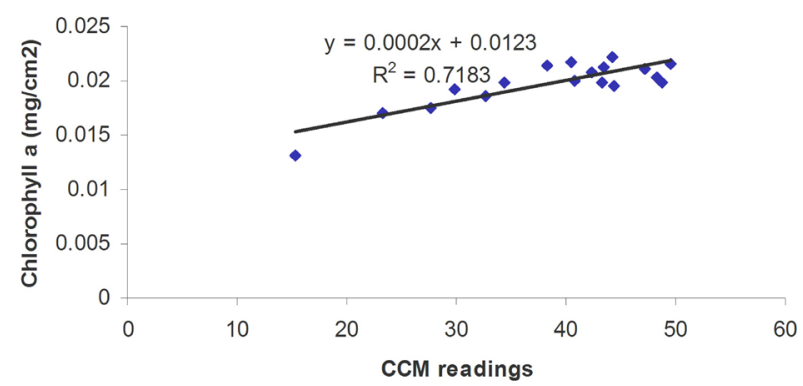

III

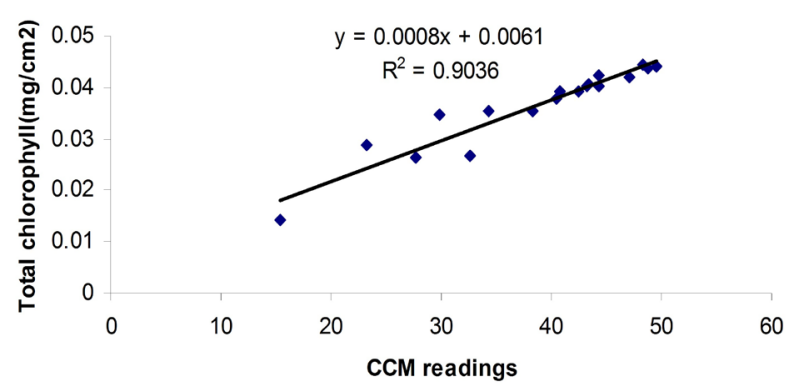

\section{Nitrogen determination}

The leaf samples (each sample containing 4 leaves) were washed with tap water, $0.01 \mathrm{~N} \mathrm{HCl}$ and then distilled water. Leaf samples were placed in oven at $60^{\circ} \mathrm{C}$ until dry weight was stable. Then the dried leaf materials were ground. The Kjeldahl method was used to measure nitrogen content of leaf samples.

All data were analyzed by SPSS v 12.0 for windows software and Excel 2002 programs.

\section{Results and discussion}

Statistical analysis showed linear correlation between CCM readings and leaf chlorophyll content and also leaf nitrogen content.

Results of chlorophyll $a\left(\mathrm{mg} / \mathrm{cm}^{-2}\right)$, chlorophyll $b(\mathrm{mg} /$ $\left.\mathrm{cm}^{-2}\right)$, total chlorophyll content $\left(\mathrm{mg} / \mathrm{cm}^{-2}\right)$ and CCM readings of the Asian pears leaves are presented in Tab. 1. Obtained data by CCM were ranged from 12.8 to 57.1 with a mean of 38.56. Chlorophyll $a$ range was from 0.013 to 0.022 with a mean of $0.0195 \mathrm{mg} / \mathrm{cm}^{-2}$ and chlorophyll $b$ range was 0.001 to $0.0242 \mathrm{mg} / \mathrm{cm}^{-2}$ with a mean of 0.0163 $\mathrm{mg} / \mathrm{cm}^{-2}$. Total extractable chlorophyll content was ranged from 0.014 to $0.044 \mathrm{mg} / \mathrm{cm}^{-2}$ with a mean of 0.0357 . Fig. 1 (I, II and III) shows correlations between chlorophyll meter readings and chlorophyll $a, b$ and total chlorophyll content in Asian pear leaves. It's mentionable that, each reading (each point) by chlorophyll meter is mean of five readings taken on one leaf. Data analysis indicated that,
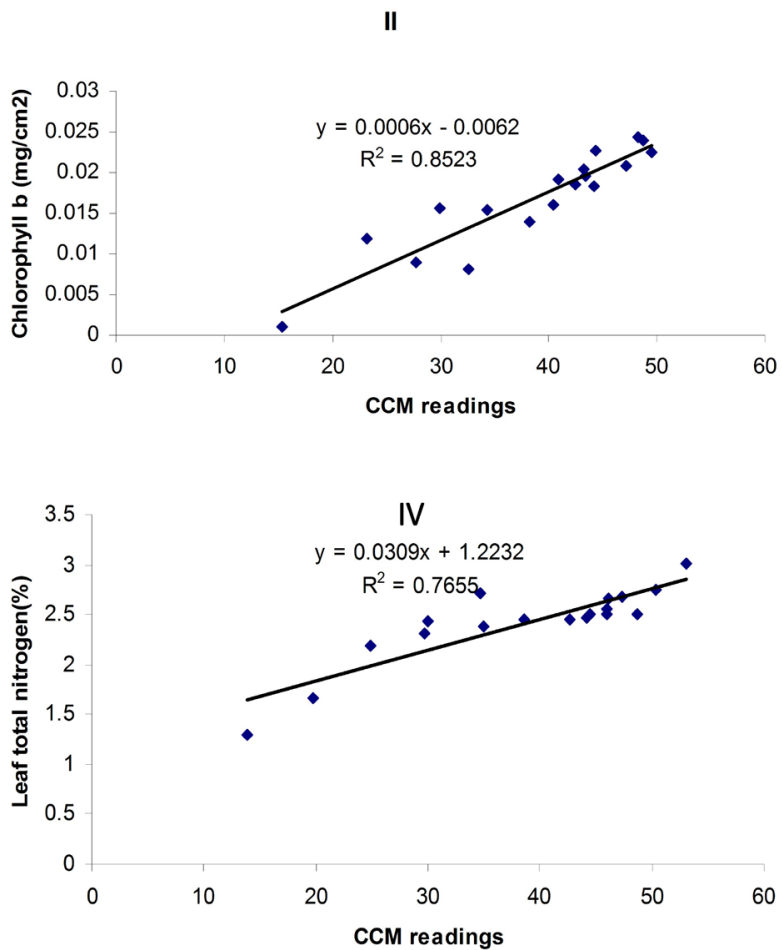

Fig.1. The linear correlation between chlorophyll meter readings and chlorophyll $a, b$, total chlorophyll content and total nitrogen (I,II, III and IV) in Asian pear leaves. Each point is average 12 measurements 
Tab. 1. Chlorophyll $a\left(\mathrm{mg} / \mathrm{cm}^{2}\right)$, Chlorophyll $b\left(\mathrm{mg} / \mathrm{cm}^{-2}\right)$, total chlorophyll content $\left(\mathrm{mg} / \mathrm{cm}^{-2}\right)$ and CCM readings in leaves of Asian pear trees

\begin{tabular}{|c|c|c|c|c|c|c|c|c|c|c|c|c|c|c|c|c|c|c|}
\hline No. tree & 1 & 2 & 3 & 4 & 5 & 6 & 7 & 8 & 9 & 10 & 11 & 12 & 13 & 14 & 15 & 16 & 17 & 18 \\
\hline $\mathrm{CCI}(\mathrm{n}=5)$ & 44.24 & 34.36 & 23.26 & 42.4 & 32.62 & 48.78 & 40.82 & 29.92 & 43.46 & 49.5 & 38.26 & 15.32 & 40.48 & 48.3 & 43.26 & 47.14 & 27.66 & 44.32 \\
\hline Chlorophyll a & 0.0221 & 0.0199 & 0.0170 & 0.0208 & 0.0186 & 0.0198 & 0.0199 & 0.0192 & 0.0211 & 0.0215 & 0.0214 & 0.0131 & 0.0217 & 0.0202 & 0.019883 & 0.0211 & 0.0180 & 0.02 \\
\hline Chlorophyll $b$ & 0.0182 & 0.0155 & 0.0117 & 0.0185 & 0.0081 & 0.0239 & 0.0192 & 0.0156 & 0.0195 & 0.0224 & 0.0139 & 0.0010 & 0.0160 & 0.0243 & 0.020473 & 0.0209 & 0.0090 & 0.023 \\
\hline Total chlorophyll & 0.0403 & 0.0354 & 0.0287 & 0.0393 & 0.0267 & 0.0437 & 0.0391 & 0.0348 & 0.0407 & 0.0440 & 0.0353 & 0.0141 & 0.0378 & 0.0446 & 0.040343 & 0.0420 & 0.0260 & 0.0420 \\
\hline
\end{tabular}

Tab. 2. Nitrogen content and CCM readings in leaf of the Asian pear trees

\begin{tabular}{|c|c|c|c|c|c|c|c|c|c|c|c|c|c|c|c|c|c|c|}
\hline No. tree & 1 & 2 & 3 & 4 & 5 & 6 & 7 & 8 & 9 & 10 & 11 & 12 & 13 & 14 & 15 & 16 & 17 & 18 \\
\hline $\mathrm{CCI}(\mathrm{n}=12)$ & 46.08 & 35.16 & 19.91 & 44.16 & 29.66 & 46 & 42.66 & 30.08 & 44.58 & 53.08 & 34.58 & 13.9 & 38.75 & 50.33 & 46 & 48.5 & 25 & 47.33 \\
\hline Nitrogen (\%) & 2.666 & 2.388 & 1.67 & 2.466 & 2.305 & 2.495 & 2.451 & 2.431 & 2.496 & 3.01 & 2.71 & 1.29 & 2.446 & 2.751 & 2.56 & 2.501 & 2.18 & 2.685 \\
\hline
\end{tabular}


94

there was linear correlation between chlorophyll $a, b$, and total chlorophyll content with obtained data by CCM. $\left(\mathrm{R}^{2}=0.718,0.852\right.$ and 0.90 , respectively). The data suggests the CCM-200 may be able to estimate of chlorophyll content in studied trees.

Leaf nitrogen percentage and CCM readings are shown in Tab. 2. The CCM readings were ranged from 10 to 63 (mean of 38.65 ) and nitrogen percentage was ranged from 1.29 to $3.00 \%$ (Fig 1) and with a mean of 2.39 . The results of nitrogen analysis in the leaves were correlated with chlorophyll meter readings as shown in Fig. 1 (IV). Each reading (each point) by chlorophyll meter is mean of twelve measurements taken on four leaves. Correlation analysis showed a linear relationship between CCM readings and nitrogen in the leaves $\left(\mathrm{R}^{2}=0.766\right)$ and nitrogen contents were found may be estimated via the following formula:

\section{Nitrogen $=0.0309 \mathrm{CCI}+1.221$}

A decrease in nitrogen percentage was obtained when the readings were less than 20. CCM-200 measurements were found to have positive correlations with total chlorophyll content and nitrogen content in Asian pear trees.

Relationship between obtained data from chlorophyll meter and nitrogen concentrations which obtained in this study was also reported by other researchers. KowalczykJusko and Koscik (2002), reported $\mathrm{R}^{2}=0.6936$ between SPAD-502 readings and nitrogen in tobacco leaves. Van den Berg ad Perkins (2004) Observed linear correlation between CCI and nitrogen concentration in sugar maple leaves $\left(R^{2}=0.64\right)$. Biber $(2007)$ had reported a significant correlation between CCI and chlorophyll $a$ content with an $\mathrm{R}^{2}=0.95$ in mangrove leaves. Chang and Robinson (2003) reported $\mathrm{R}^{2}=0.73$ for SPAD-502 readings and $\%$ nitrogen in Green ash. Also Richardson et al. (2002) found an $\mathrm{R}^{2}=0.958$ between chlorophyll content and CCI in paper birch (Betula papyrifera) leaves. Shaahan et al. (1999) had reported $\mathrm{R}^{2}=0.99$ between chlorophyll content and CCI in mandarin and grapevine. Wright et al. (2009) had reported chlorophyll fluorescence also can be used for non-destructively measure changes in water status of grape in storage. From the present work, it can be concluded chlorophyll content meter CCM-200 can be used for predicting both chlorophyll and nitrogen in Asian pear trees under field condition.

\section{References}

Arnon DI (1949). Copper enzymes in isolated chloroplasts. Polyphenoloxidase in Beta vulgaris. Plant Physiology 24:115.

Biber PD (2007). Evaluating a chlorophyll content meter on three coastal wetland plant species. Journal of Agricultural, Food and Environmental Sciences 1(2):1-11.
Chang SX, Rabinson DJ (2003). Nondestructive and rapid estimation of hardwood foliar nitrogen status using the SPAD-5O2 chlorophyll meter. Forest Ecology and Management 181:331-338.

Hiscox JD, Israelstam GF (1979). A method for the extraction of chlorophyll from leaf tissue without maceration. Canadian Journal of Botany 57:1332-1334.

Kowalczyk-Jusko A, Koscik B (2002). Possible use of the chlorophyll meter (SPAD-502) for evaluation nitrogen nutrition of the Virginia tobacco. Electronic Journal of Polish Agricultural Universities 5(1):05.

Naumann JC, Young DR, Anderson JE (2008). Leaf chlorophyll fluorescence, reflectance, and physiological response to freshwater and saltwater flooding in the evergreen shrub, Myrica cerifera. Environmental and Experimental Botany 63:402-409.

Pavan G, Jacquemoud S, Rosny GD, Rambaut JP, Frangi JP, Bidel LPR, Francois C (2004). Ramis: A new portable field radiometer to estimate leaf biochemical content. Seventh international conference on precision agriculture and other precision resources management, 25-28 July 2004, Minneapolis.

Richardson AD, Duigan SP, Berlyn GP (2002). An evaluation of noninvasive methods to estimate foliar chlorophyll content. New Phytologist 153:185-194.

Shaahan MM, El-Sayed AA, Abou El-Nour EAA (1999). Predicting nitrogen, magnesium and iron nutritional status in some perennial crops using a portable chlorophyll meter. Scientia Horticulturae 82:339-348.

Van den Berg AK, Perkins TD (2004). Evaluation of portable chlorophyll meter to estimate chlorophyll and nitrogen contents in sugar maple (Acer saccharum Marsh.) leaves. Forest Ecology and Management 200:113-117.

Wright H, DeLong J, Lada R, Prange R (2009). The relationship between water status and chlorophyll a fluorescence in grapes (Vitis spp.). Postharvest Biology and Technology 51:193-199.

Wu C, Niu Z, Tang Q, Huang W (2008). Estimating chlorophyll content from hyperspectral vegetation indices: Modeling and validation. Agricultural and Forest Meteorology 48:1230-1241. 